\title{
Evaluation of the effectiveness of backfilling and sealing at an open-pit mine using ground penetrating radar and geoelectrical surveys, Kimheden, northern Sweden
}

\author{
Lucile Villain • Nils Sundström • Nils Perttu • \\ Lena Alakangas $\cdot$ Björn Öhlander
}

Received: 17 March 2014/ Accepted: 24 September 2014/Published online: 11 October 2014

(C) The Author(s) 2014. This article is published with open access at Springerlink.com

\begin{abstract}
At Kimheden, a small copper mine in northern Sweden, reclamation of the two open pits was investigated using ground penetrating radar and geoelectrical multiplegradient array measurements. The pits had been backfilled with waste rock, with a dry cover being applied on top in 1996 in order to reduce the influx of oxygen to the sulphidic mine waste and the subsequent production of acid mine drainage. The dry cover consists of a sealing layer of clayey till and a protective layer of unsorted till. As geochemical sampling in the drainage from the pits had previously revealed the continued release of contaminating oxidation products, the purpose of the geophysical survey undertaken in 2010 was to identify deficiencies in the cover or other pathways for oxygen to reach the waste rock. The radar images did not reveal any damage in the sealing layer but risks of deterioration of the cover in the long term were identified with both the radar and geoelectrical data. The radar localised regions of thinner protective layer where the sealing layer could be exposed to frost action. The geoelectrical measurements indicated the existence of seepage through the dry cover that presented a risk of erosion of the sealing layer. 2-D inversion of geoelectrical data also imaged some pathways of groundwater around the main pit. The results from the geophysical investigations were used together with other site data in order to show that both deficiencies in the cover and superficial fractures in the pit walls may explain an ongoing influx of oxygen to the mine waste.
\end{abstract}

L. Villain $(\varangle)$ N. Sundström · N. Perttu · L. Alakangas ·

B. Öhlander

Division of Geosciences and Environmental Engineering, Luleå University of Technology, 97187 Luleå, Sweden

e-mail: lucile.villain@1tu.se
Keywords Ground penetrating radar (GPR) - Direct current (DC) resistivity - Mine waste - Reclamation assessment · Open pit · Dry cover

\section{Introduction}

Solutions to control contaminated drainage from mines have been the subject of intense discussions over the last few decades. Prevention and mitigation methods at the source have been promoted as an economic and practical alternative to treatment of the polluted water. In this approach, efforts are concentrated on limiting the reactions that generate contaminants and the subsequent leaching and transport of the reaction products (INAP 2009), rather than treating the contaminants in the drainage.

At coal and hard rock mines, toxic metal-rich acid mine drainage (AMD) may be produced from the oxidation of sulphide rocks as they are exposed to water and oxygen. Prevention and mitigation, in this case, generally includes the reduction of water and/or oxygen contact with the sulphidic mining residues. Different measures may be applied, including diversion of surface water from reactive areas or other types of water management, conditioning of the tailings through e.g. compaction or desulphurisation, disposal of the waste under water or various types of soil covers to limit oxygen ingress (INAP 2009).

Monitoring the effects of the mitigation actions on the quality of the mine drainage gives essential data when evaluating the need for further reclamation and improvements in remediation techniques. Monitoring programmes at reclaimed sites often consist of regular hydrogeochemical studies including sampling of surface water, groundwater, sediments and mine waste as well as measurement of water flows and groundwater levels. Some post- 
reclamation studies can be found in the peer-reviewed literature, such as Holmström et al. (2001), Brake et al. (2001), Bambic et al. (2006) and Runkel et al. (2009). A carefully planned sampling programme may provide detailed data about the generation, transport and mitigation processes affecting the contaminants. Common hydrogeochemical studies, nevertheless, usually generate local results, making it difficult to appreciate water properties and quality across the entire site. In this regard, indirect geophysical methods that have the potential to image the contaminated drainage can be used to increase the understanding of the distribution of contaminants at the site and to support local sampling results. Moreover, they can provide other types of information about the subsurface, such as the presence of fractures in the bedrock, the depth of the soil-bedrock interface or the location of underground workings.

Provided that good background site data are available, geophysical techniques have the advantage of being nonintrusive and cost-efficient. In water-related studies, they may be used for hydrogeological mapping, estimation of hydrological parameters and monitoring of hydrological processes (Rubin and Hubbard 2005). Due to the ability of electrical and electromagnetic techniques to image groundwater and sometimes determine its quality, they have proven useful in environmental studies. Electrical resistivity imaging, ground penetrating radar and induced polarisation methods have been widely employed in studies of leachate transport from landfills (Nobes et al. 2000; Abu-Zeid et al. 2004; Porsani et al. 2004; Dahlin et al. 2010). They have also been used in mining environmental studies, in order to image AMD plumes (Buselli and Lu 2001; Rucker et al. 2009), tailings ponds (PlacienciaGómez et al. 2010; Martín-Crespo et al. 2010) or waste rock piles (Van Dam et al. 2005; Poisson et al. 2009; Anterrieu et al. 2010; Mele et al. 2013). This study uses ground penetrating radar (GPR) and geoelectrical multiplegradient array surveying to examine the effectiveness of the backfilling and sealing of mine waste at a small openpit copper mine in northern Sweden. The investigation is in line with the previous studies cited, although it differs in the objects surveyed, as the geophysical combined study of a backfilled open pit and its dry cover has not been covered by any of these studies.

Mitigation of AMD generation at the Kimheden openpit mine involved the progressive backfilling of waste rock into two small open pits and the deposition, in 1996, of a composite till dry cover on top to reduce the influx of oxygen into the waste. A previous geochemical study at the site (Villain et al. 2013) demonstrated that, in spite of the large decrease of $\mathrm{Cu}$ and $\mathrm{Zn}$ concentrations in the mine drainage since the beginning of the reclamation, water quality at the mine is still unsatisfactory, which may be due to inadequacies of the mitigation methods used. It is suspected that the control of oxygen transport to the backfilled waste has failed to decrease the rate of sulphide oxidation in the rocks to an acceptable level. In this case, it is important to know what has prevented an effective reduction of oxygen intrusion to the waste.

The purpose of the study was to identify potential pathways for oxygen to reach the sulphidic waste despite backfilling and sealing, as well as other possible deficiencies of the mitigation measures. In this regard, two objectives were set: (1) characterise the dry cover and its integrity and (2) image the location of the mine waste, groundwater, contaminated water and potential fractures in the pit walls at backfilled open pit 1 , the pit that generates the greatest quantity of contaminants.

\section{Study site}

Site location, geological and hydrological context

Kimheden is a small copper mine situated in the Kristineberg mining area (Fig. 1a) in the county of Västerbotten, northern Sweden. The local climate is cold, with a yearly average air temperature of $0.7^{\circ} \mathrm{C}$ and 5 months with an average temperature below $0{ }^{\circ} \mathrm{C}$ (Malmström et al. 2001). Annual precipitation at the site is $\sim 400$ to $800 \mathrm{~mm}$ (Axelsson et al. 1991), accumulating in the form of snow from October to May.

The bedrock in the Kristineberg area is composed of deformed and metamorphosed Palaeoproterozoic $1.9 \mathrm{Ga}$ volcanic and sedimentary rocks hosting several volcanic massive sulpide (VMS) deposits of varying size, the most important being the Kristineberg deposit. These deposits are thought to have formed in a continental or mature extensional arc setting (Allen et al. 2002). Intense synvolcanic hydrothermal alteration has affected the volcanic rocks prior to metamorphism. The Kimheden deposit, of interest in this study, formed during the early stages of felsic volcanism (Hannington et al. 2003). It is one of the smaller pyrite-rich massive sulphide deposits in the area, which are intercalated within a succession of felsic and minor mafic meta-volcaniclastic rocks. The mineralisation is principally composed of pyrite, chalcopyrite and sphalerite while the ore-hosting rocks are quartz-muscovitechlorite \pm biotite schists. Both the deposits and the host rocks have been largely deformed.

The mine lies on the side of a hill, with an altitude range of 470 to $520 \mathrm{~m}$. The mineralisation is striking in the northeastern direction, which is also the direction of the two open pits of the site (Fig. 1b). The bedrock is covered by 1 to $2 \mathrm{~m}$ thick glacial till, locally overlain by a thin layer of peat (Hellman and Lokrantz 2008). 

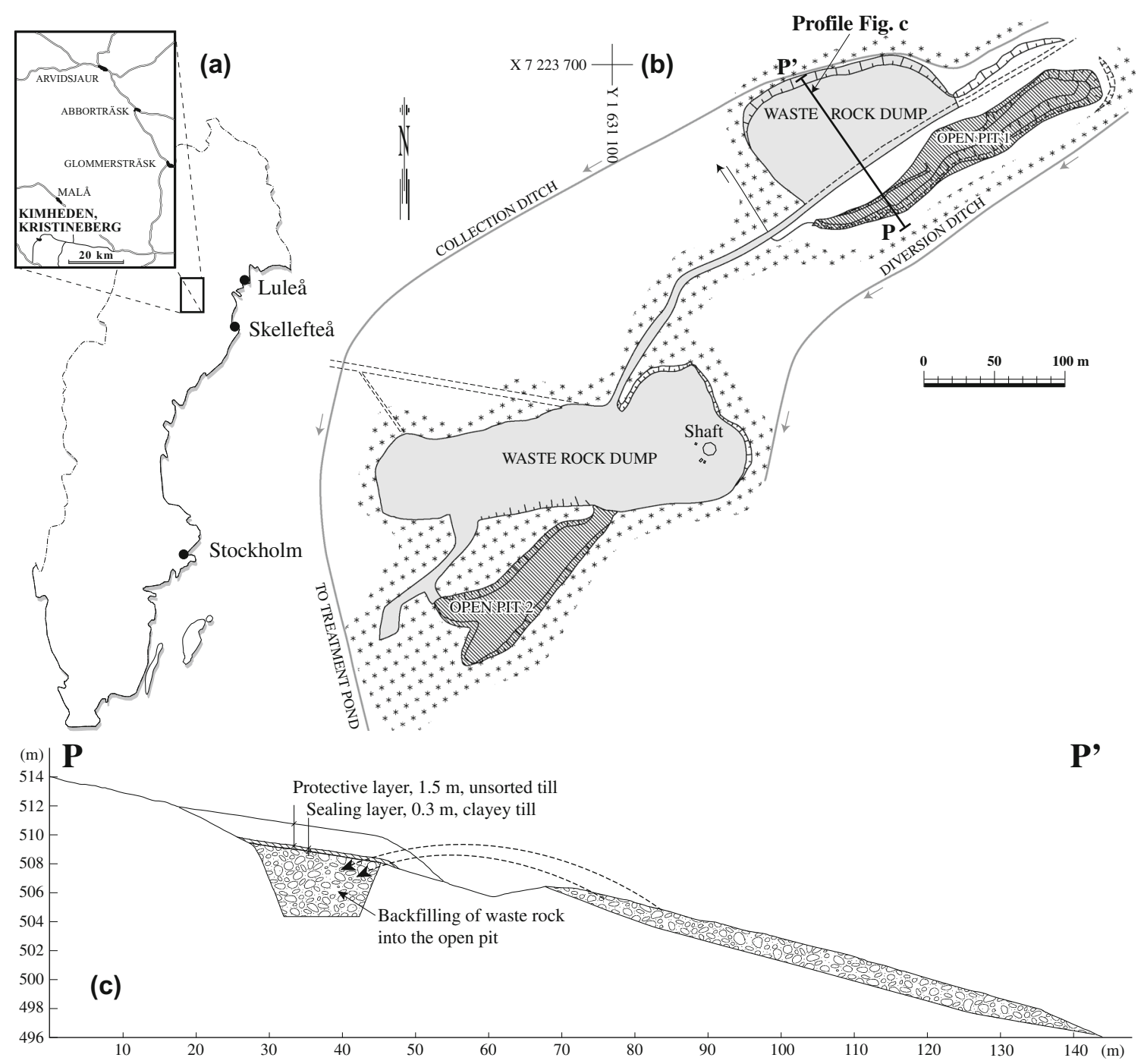

Fig. 1 a Location of Kimheden and the Kristineberg mining area in northern Sweden. b Schematical map of the site in the beginning of the reclamation activities (early 1980s). The two open pits of the mine are indicated, as well as water management ditches and former waste rock dumps. The coordinates are given in the Swedish coordinate reference system RT90 2.5 gon V. c Cross section of open pit 1 showing the backfilling and sealing process completed in 1995-1996. The dry cover consists of $0.3 \mathrm{~m}$ clayey till (the sealing layer) overlain by $1.5 \mathrm{~m}$ unsorted till (the protective layer)

underground and in two open pits (Fig. 1b). The eastern open pit, hereafter referred to as open pit 1, is $210 \mathrm{~m}$ long, and the western open pit or open pit 2 is $140 \mathrm{~m}$ long; both are approximately $20 \mathrm{~m}$ wide and less than $\sim 15 \mathrm{~m}$ deep. The total tonnage extracted was $0.13 \mathrm{Mt}$ with a grade of $0.95 \% \mathrm{Cu}$ (Årebäck et al. 2005). Waste rock left from mining was dumped in the proximity of the pits, exposed to rainwater and oxygen, and was quickly affected by sulphide oxidation with the subsequent production of $\mathrm{Cu}$ and Zn-rich AMD.

As a consequence of the uncontrolled release of contaminated water, a network of ditches was excavated in 1981-1982 (Fig. 1b), in order to reduce water run-off to the waste rock and to collect the mine drainage in a treatment

At Kimheden, copper ore was mined by the Swedish mining company Boliden AB between 1968 and 1974, 
pond downstream of the hill. Later on, the waste rock was disposed of into the pits in different stages to limit the area of contamination. Reclamation activities were completed in 1995-1996, when the open pits were fully backfilled with the waste rock left and a dry cover was placed on top (Fig. 1c). The dry cover was meant to reduce the transport of oxygen to the mining waste by using a layer of $0.3 \mathrm{~m}$ clayey till (sealing layer) overlain by $1.5 \mathrm{~m}$ unsorted till (protective layer). The moisture retention capacity of such a type of sealing layer has previously been shown to significantly inhibit the diffusion of oxygen into underlying waste deposits (Höglund and Herbert 2004). Geotechnical tests before the application of the dry cover showed that the material used in the sealing layer contained about $8 \%$ clay and had a hydraulic conductivity of $\sim 1 \times 10^{-9} \mathrm{~m} \mathrm{~s}^{-1}$ (Edström and Schönfeldt AB 1996). The actual thickness of the protective layer is investigated in this study.

\section{Methodology}

The GPR survey was carried out over 3 days at the beginning of June 2010. The ground was free from snow, but there were possibly remains of frost in the subsurface soil. The geoelectrical survey was carried out at the beginning of October 2010. It is assumed that there was no frost in the subsurface then and the surface was snow-free.

The geophysical measurements were carried out along survey lines organised in grids. In the GPR survey, two grids were used, one on each backfilled open pit (Fig. 2). In the geoelectrical survey, one grid of four lines 200 to $280 \mathrm{~m}$ long was used on backfilled open pit 1 and the surrounding bedrock. The central lengthwise line of the GPR grid on backfilled open pit 1 is a part of line 1 of the geoelectrical grid. Elevation measurements were made using a levelling instrument along all lines.

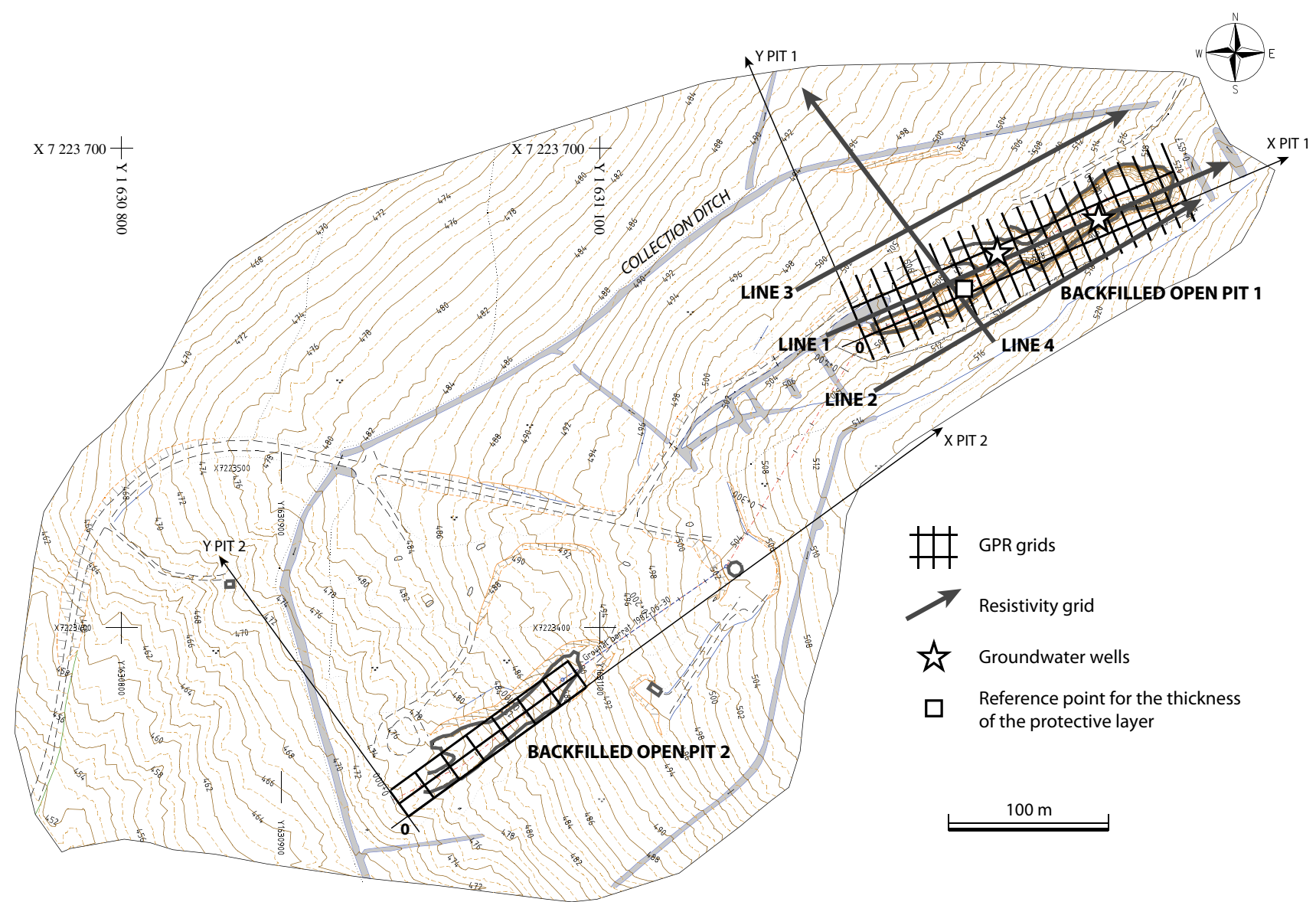

Fig. 2 Locations of the GPR and geoelectrical survey grids at the Kimheden mine site. The $(x, y)$ GPR coordinate systems used in "Analysis of GPR data" and "Thickness of the protective layer" are introduced here. The positions of the two groundwater wells installed in the backfill of open pit 1 and of the reference point for the thickness of the protective layer are also shown. Situation of the map in the Swedish coordinate reference system RT90 2.5 gon V is indicated 
Ground penetrating radar

\section{GPR measurements}

The GPR survey was carried out using a RAMAC GPR system from Malå Geoscience. Measurements were made every $5 \mathrm{~cm}$ along each survey line of the two GPR grids on the backfilled open pits (Fig. 2); the measurements were triggered using a "hip chain". Each line was investigated using a shielded $250 \mathrm{MHz}$ antenna with the intention of mapping the sealing layer which was expected to be located at a depth of $1.5 \mathrm{~m}$. Note that a higher frequency antenna (yielding a higher vertical resolution) would have been more suitable to investigate the sealing layer itself, which is about $30 \mathrm{~cm}$ thick. However, preliminary tests at the site showed that measurements conducted with higher frequency antennas (500 and $800 \mathrm{MHz}$ ) could not provide a sufficient penetration depth. In addition, reference measurements in air were conducted for the time-zero correction.

\section{Analysis of GPR data}

A major objective of the GPR survey was to create maps of the thickness of the protective layer, i.e. depth of the sealing layer, in the dry cover. Determining the thickness of the till protective layer from the two-way travel times requires the GPR wave propagation velocity to be known at each measurement point. Therefore, two propagation velocity models in the protective layer were built, one for each of the backfilled open pits. The models were based on the velocities estimated from the two-way travel times of the direct waves as follows.

At backfilled open pit 1, the humidity of the till was observed to be highest in the south-west end of the pit $\left(x_{\text {pit_1 }}=0\right)$, and decrease in the $x$-direction towards the other end (Fig. 2). As it is reasonable to assume that any larger variation in the velocity of the direct wave is mainly dependent on the amount of pore water in the soil, the velocity model of this pit was established as a function of $x_{\text {pit_1 }}$ (Fig. 3). This function was obtained by fitting a 5 th order polynomial curve to the velocity values estimated from the direct waves measured at all measurement points on the central lengthwise survey line $\left(y_{\text {pit_1 }}=10 \mathrm{~m}\right.$, Fig. 2). At backfilled open pit 2, since no large variation in the velocity of the direct wave was observed, the velocity model was simply taken as a constant calculated as the mean of the velocities estimated from the direct wave at each measurement point along the central lengthwise survey line $\left(y_{\text {pit_2 }}=10 \mathrm{~m}\right.$, Fig. 2), namely $v_{\text {till }}=0.1053 \mathrm{~m} \mathrm{~ns}^{-1}$.

In order to create models of the thickness of the protective layer at both pits, attempts were made to identify the reflection of the sealing layer on each GPR profile. With the data from backfilled open pit 2 , the sealing layer could fairly easily be

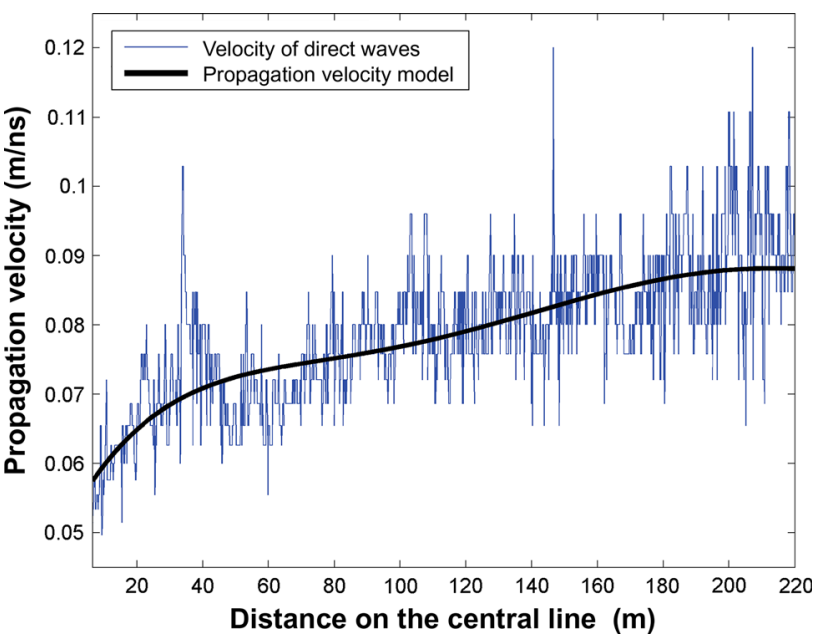

Fig. 3 Propagation velocity model of GPR waves in the protective layer of backfilled open pit 1

distinguished within the reflections visible in the GPR profiles. On the other hand, data obtained from backfilled open pit 1 showed many reflections that could be confused with the sealing layer. In order to select the correct reflection, some reference point was required. Such a reference point was found from archive data, where the thickness of the protective layer was measured as $1.5 \mathrm{~m}$ during a field geotechnical control in 1996, shortly after deposition of the dry cover (the reference point is indicated on Fig. 2). Providing that no significant compaction of the protective layer has occurred since then, and using the reference point together with the velocity model, the most probable reflection from the sealing layer could be identified on the survey profile closest to this point. In each of the remaining profiles, the reflection interpreted as the sealing layer was identified by comparing its depth at the intersection with the previously analysed crossing profile, to make sure that the same reflection was chosen. This was an iterative process, carried out until all the intersection points fitted together. Finally, the data obtained from all survey profiles were used to create 3-D plots, depicting the thickness of the protective layer at both open pits.

\section{Geoelectrical multiple-gradient arrays}

Geoelectrical data were collected using the ABEM Lund Imaging system (Dahlin and Zhou 2006) with a multiplegradient array with a minimum electrode distance of $2 \mathrm{~m}$. This configuration with the SAS4000 Terrameter permits multi-channel measurements, with four potential readings for each pair of current electrodes. The gradient array has been shown to be particularly adapted to multiple-channel measurements and to provide a substantial data density with good vertical-horizontal resolution in a reasonable amount of time (Dahlin and Zhou 2006). Each measurement was 
Table 1 Characteristics of the geoelectrical multiple-gradient array survey

\begin{tabular}{lllll}
\hline Profile & $\begin{array}{l}\text { Length } \\
(\mathrm{m})\end{array}$ & $\begin{array}{l}\text { Number of } \\
\text { electrodes }\end{array}$ & $\begin{array}{l}\text { Number of } \\
\text { measurement } \\
\text { points }\end{array}$ & $\begin{array}{l}\text { Number of } \\
\text { stacks }\end{array}$ \\
\hline Profile 1 & 280 & 141 & 1,791 & $2-4$ \\
Profile 2 & 240 & 121 & 1,809 & $2-4$ \\
Profile 3 & 240 & 121 & 1,800 & $2-4$ \\
Profile 4 & 200 & 101 & 1,470 & $2-4$ \\
\hline
\end{tabular}

stacked two to four times. In backfilled areas covered by resistive till, problems were encountered in injecting sufficient current into the ground. In order to decrease the contact resistance between electrodes and the ground, salt water and extra current electrodes were therefore used when needed. The data were inverted to direct current (DC) resistivity using RES2DINV (Geotomo Software) with the robust L1norm sharp boundary inversion constrain (Loke et al. 2003). To support the interpretation of the inverted resistivity sections, forward models of apparent resistivity configurations were constructed using RES2DMOD (Geotomo Software). Details about the measurements and analysis of the data are summarised in Table 1 . With this array, the maximum penetration depth is $\sim 20$ to $30 \mathrm{~m}$ (Dahlin and Zhou 2006). However, the actual penetration depth depends on measurement limitations such as noise and contact resistance, and on the resistivity distribution of the subsurface.

\section{Reference measurements}

Some field measurements were carried out to serve as a reference for data interpretation. Groundwater level was measured with an electric dip meter inside two groundwater wells situated in the backfill of open pit 1 (Fig. 2). Electrical conductivity was measured with a WTW Multi 350i multimeter in groundwater samples taken from the same wells, and in surface water samples collected close to backfilled open pit 1 . Observations of the depth of the sealing layer at four sample pits, excavated in the cover of backfilled open pit 2 during a later geotechnical field control in 2013, were used for comparison with the model of the thickness of the protective layer obtained with GPR at this pit.

\section{Results and discussion}

\section{Dry cover}

\section{Thickness of the protective layer}

First, identification of the sealing layer, as described in "Analysis of GPR data", was achieved on each GPR profile. The depth of the sealing layer-i.e. thickness of the protective layer-from all GPR profiles was plotted together on a 3-D model for each of the backfilled open pits. Figure $4 a, b$ shows the view of the plot from above for backfilled open pits 1 and 2, respectively.

According to the constructed models presented in Fig. 4, the thickness of the protective layer varies from $\sim 1$ to $\sim 2.3 \mathrm{~m}$ on backfilled open pit 1 , and from $\sim 1$ to $\sim 2 \mathrm{~m}$ on backfilled open pit 2 . The model obtained at backfilled open pit 2 is supported by the thickness of the protective layer observed at the four locations where sample pits were excavated (Fig. 4b). Minor deviations $(<0.4 \mathrm{~m})$ between the model and the actual thickness were noted at two sample pits $\left(x_{\text {pit_2 }}=114 \mathrm{~m} ; y_{\text {pit_2 }}=2 \mathrm{~m}\right.$ and $x_{\text {pit_2 }}=127 \mathrm{~m} ; y_{\text {pit_2 }}=10 \mathrm{~m}$ ) which may be explained by uncertainties in the model interpolation for the sample pit outside of any GPR survey line $\left(x_{\text {pit_2 }}=114 \mathrm{~m}\right.$; $y_{\text {pit_2 }}=2 \mathrm{~m}$ ), and by uncertainties in the input data of the model for the other sample pit located on the central survey line $\left(x_{\text {pit_2 }}=127 \mathrm{~m} ; y_{\text {pit_2 }}=10 \mathrm{~m}\right)$-see discussion of the uncertainties in the interpretation of the data in "GPR survey". In the latter case, careful second look at the GPR profile showed that the error might have lied in the choice of the reflection for the sealing layer, whereby two distinct reflections could be found at close depths, and the lower one was selected, while the upper one might have been more appropriate. It was suspected, at this second look, that the two reflections represented the top and bottom surfaces of the sealing layer ( $\sim 30 \mathrm{~cm}$ difference in depth). In spite of these small deviations, both the GPR models obtained and the sample pits indicate an evident irregularity in the thickness of the protective layer and regions where the layer is thinner than the expected $1.5 \mathrm{~m}$ thickness. Some illustrations of the reflections found on the GPR profiles are provided in Fig. 5 (the positions of the corresponding profiles are shown in Fig. 4). All three profiles shown were obtained at backfilled open pit 2, where the GPR results were more distinct than at backfilled open pit 1 (see "GPR survey").

The data obtained with the geoelectrical survey compare well with the results of the thickness of the protective layer obtained with GPR. Due to the uncertainty in the absolute depth values from the geoelectrical data inversion, no attempt has been made to estimate exact values for the thickness of the protective layer using these data. However, a distinct variation in thickness was observed, in the same range as observed with GPR $(\sim 1 \mathrm{~m})$.

\section{Integrity of the sealing layer}

On each GPR profile, the reflection interpreted as the sealing layer was investigated to evaluate the continuity of the layer and detect significant irregularities such as 
Fig. 4 Map of the thickness of the protective layer in the dry cover on a backfilled open pit 1 and $\mathbf{b}$ backfilled open pit 2 . The $(x, y)$ coordinate systems employed are the ones introduced for the GPR grids in Fig. 2. The GPR survey lines did not cover the whole surface of backfilled open pit 2, which explains why there are blank areas in the pit. In $\mathbf{b}$, the profiles shown in Fig. 5 are positioned and the actual thickness of the protective layer observed at the four sample pits of backfilled open pit 2 is provided (a) Backfilled open pit 1

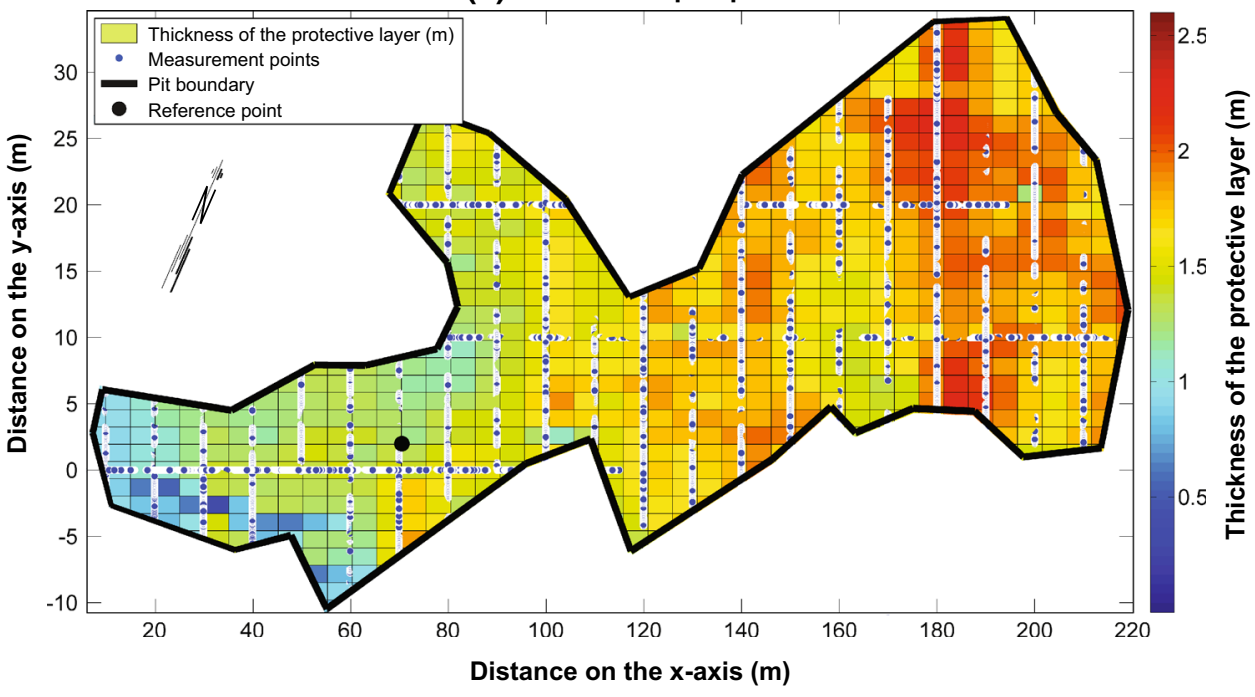

(b) Backfilled open pit 2

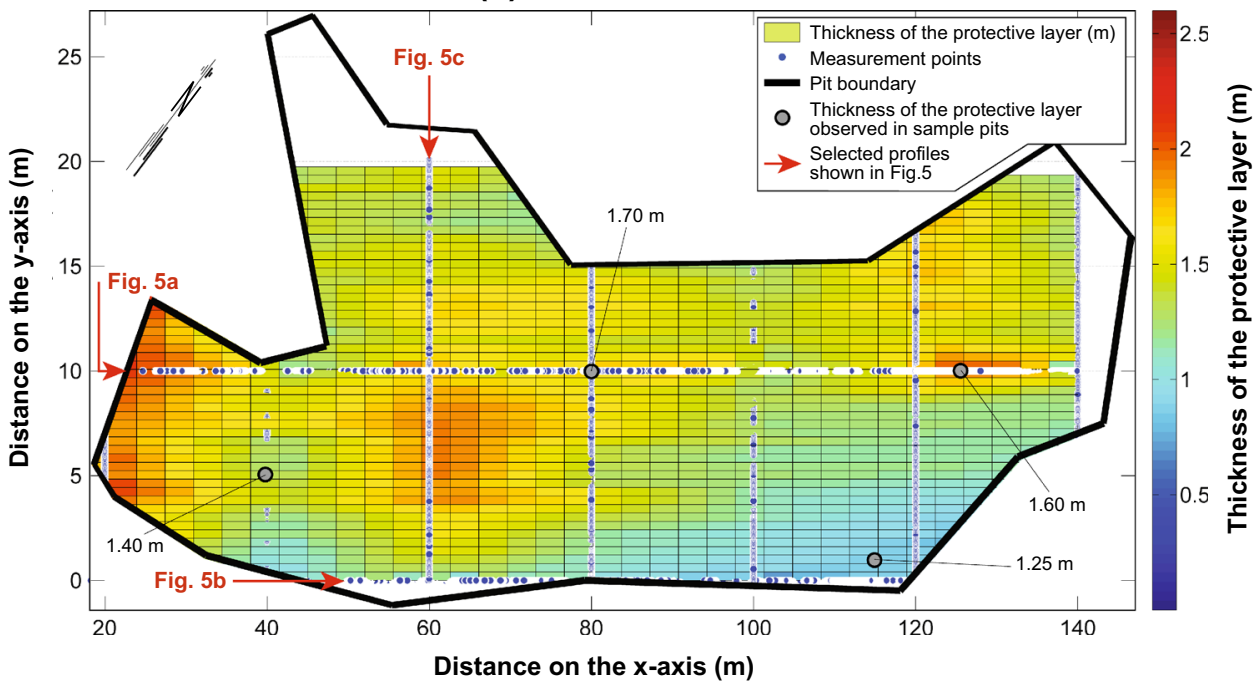

fractures and deformations. The attention was turned to backfilled open pit 2 where the sealing layer reflections were more clearly recognisable. No obvious sign of interruption or displacement of the sealing layer could be distinguished. Small-scale fractures can be recognised as hyperbolas in radargrams. Nevertheless, this signature may also characterise bigger boulders in the uppermost till layer or in the underlying waste rock, and it should therefore not be systematically interpreted as a fracture. The same caution in not over-interpreting hyperbolic patterns was expressed by Bergström (1997). Although in a few profiles some hyperbolas were seen close to the sealing layer reflection, no additional pattern such as vertical displacement of the reflection was observed, so these profiles were not interpreted as ones with fractures.

Due to the limited thickness of the sealing layer $(\sim 0.3 \mathrm{~m})$ and insufficient petrophysical contrast with the surrounding material, the layer could not be visualised in the resistivity models. However, variations in resistivity in the uppermost protective layer may reveal zones of erosion in the sealing layer. Profile 4 crossing open pit 1 exhibits a zone of reduced resistivity affecting the protective layer above the lower edge of the pit (Fig. 6d). The position and shape of the resistivity anomaly suggest that, at this location, drainage water may be seeping out from the mine waste up to the surface (or subsurface) through the sealing layer. 
Fig. 5 Selected profiles obtained with GPR on the cover of backfilled open pit 2 . The highlighted trace represents the reflection interpreted as being caused by the sealing layer. a Portion of profile over the central lengthwise line of the pit. b Portion of profile over the lower lengthwise line of the pit. c Profile along the width of the pit. All three profiles are positioned in Fig. 4

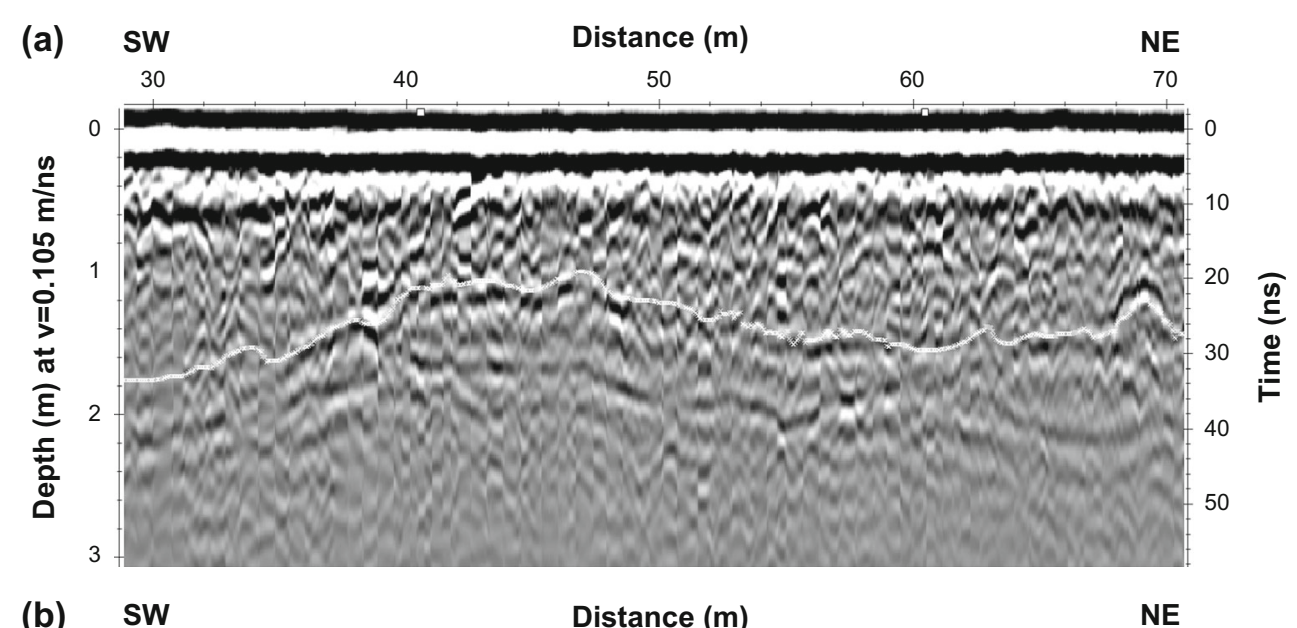

(b)
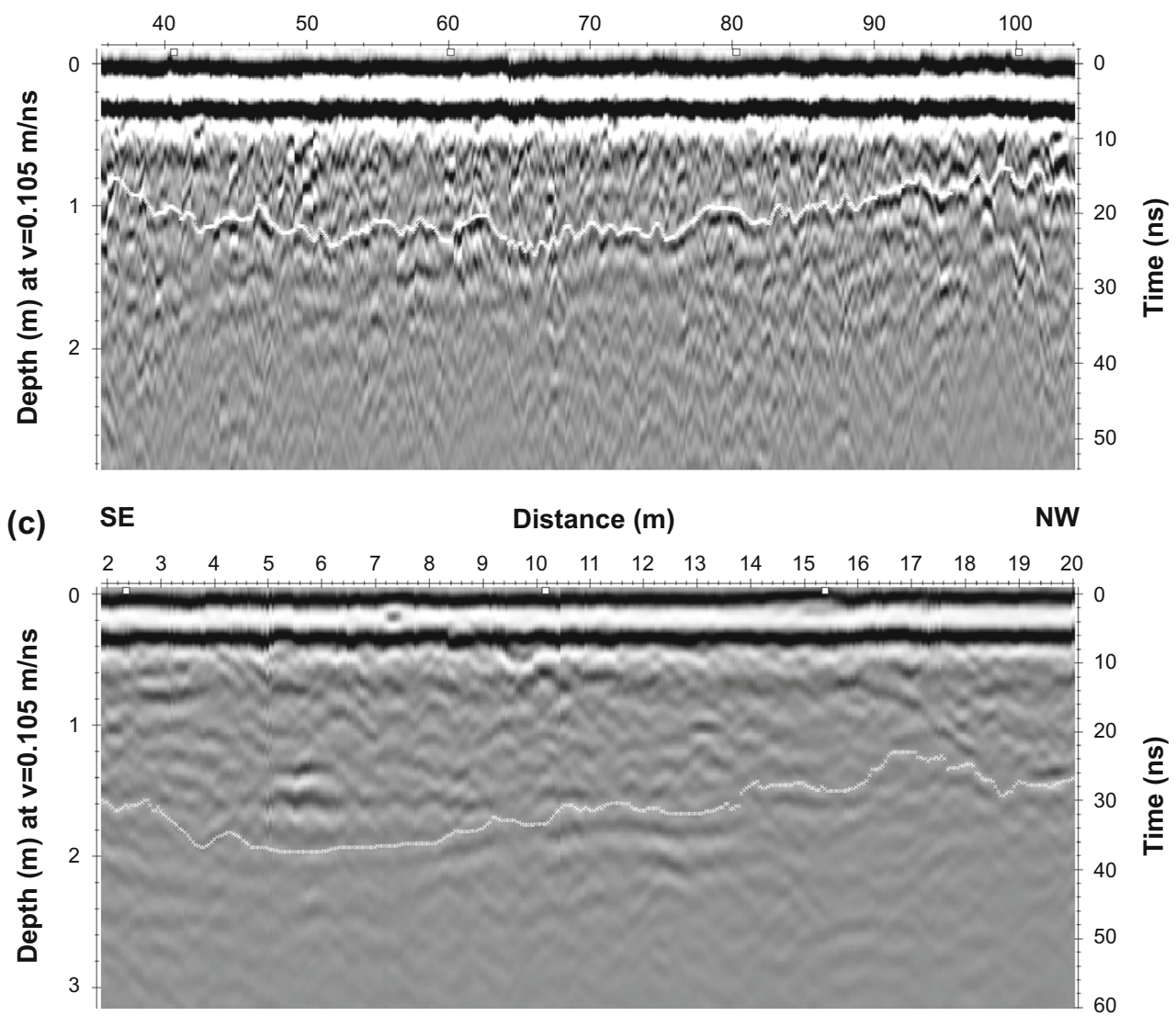

Backfilled mine waste and water pathways at backfilled open pit 1

\section{Mine waste in backfilled open pit 1}

The mine waste deposited at the site is of the same petrological nature as the surrounding bedrock, i.e. a combination of felsic volcanic and sulphidic rocks. The resistivities of these rocks are very variable. Tavakoli et al. (2012) performed petrophysical measurements on various rocks from the central Skellefte district to which the site is belonging, and they found that felsic volcanic rocks had a median resistivity of $11,550 \Omega \mathrm{m}$ with a standard deviation of $17,319 \Omega \mathrm{m}$ and sulphide ores had a median resistivity of $5,804 \Omega \mathrm{m}$ with a standard deviation of $13,041 \Omega \mathrm{m}$. Profile 1 in Fig. 6a is the inverted resistivity profile across the length of backfilled open pit 1 . The backfilled waste can be recognised by its characteristically low electrical resistivity values ( $\sim 10$ to $400 \Omega \mathrm{m}$ ) in direct contrast with the surrounding bedrock and the dry cover $(>1,000 \Omega \mathrm{m})$. Low resistivity (or high conductivity) in the backfilled waste rock may be partly explained by the relatively high 
Fig. 6 2-D inverted resistivity profiles of lines 1 to 4 in the region of backfilled open pit 1 (see Fig. 2 for the positions of the lines) (a)

Profile 1

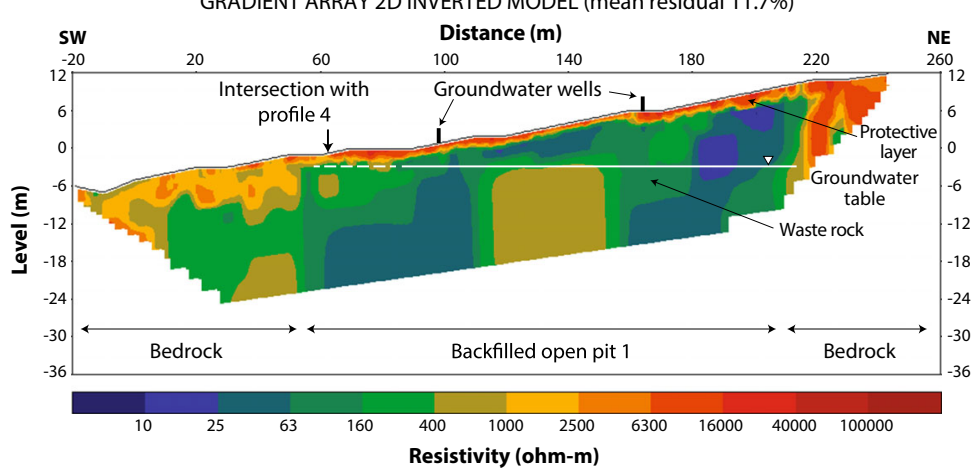

(b)

Profile 2

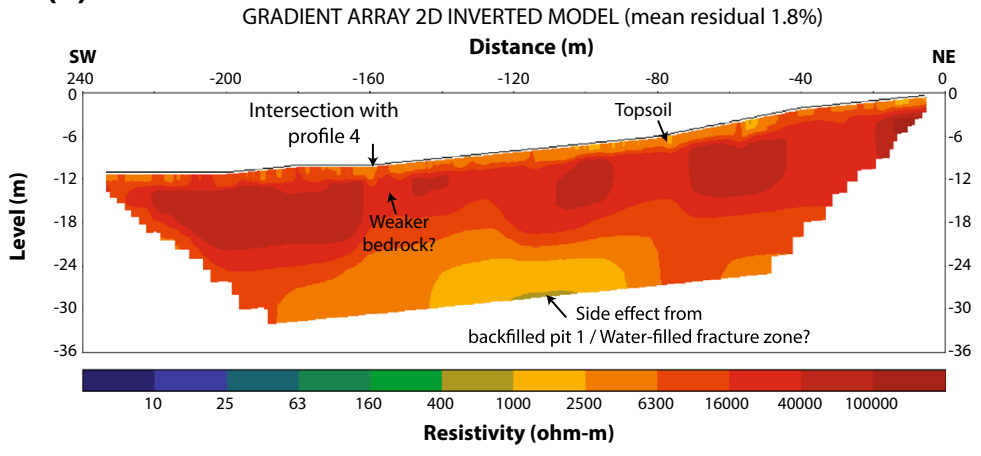

(c) Profile 3

GRADIENT ARRAY 2D INVERTED MODEL (mean residual 2.4\%)

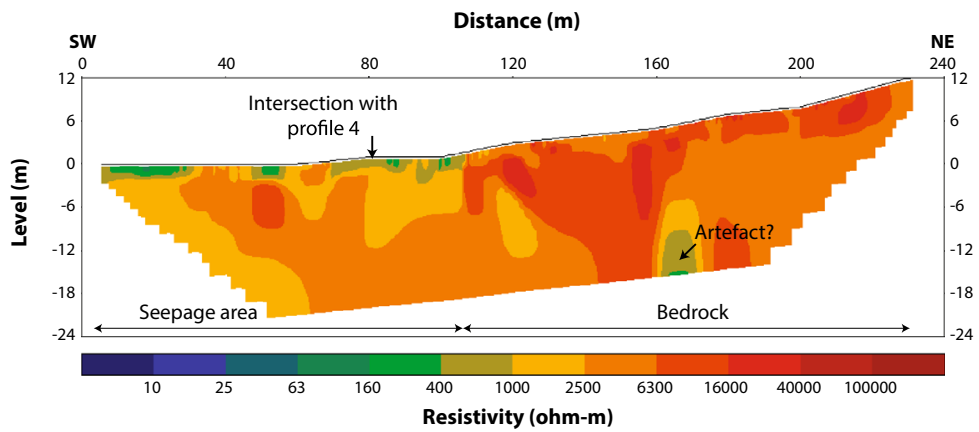

(d)

Profile 4

GRADIENT ARRAY 2D INVERTED MODEL (mean residual 3.6\%)

Distance (m)

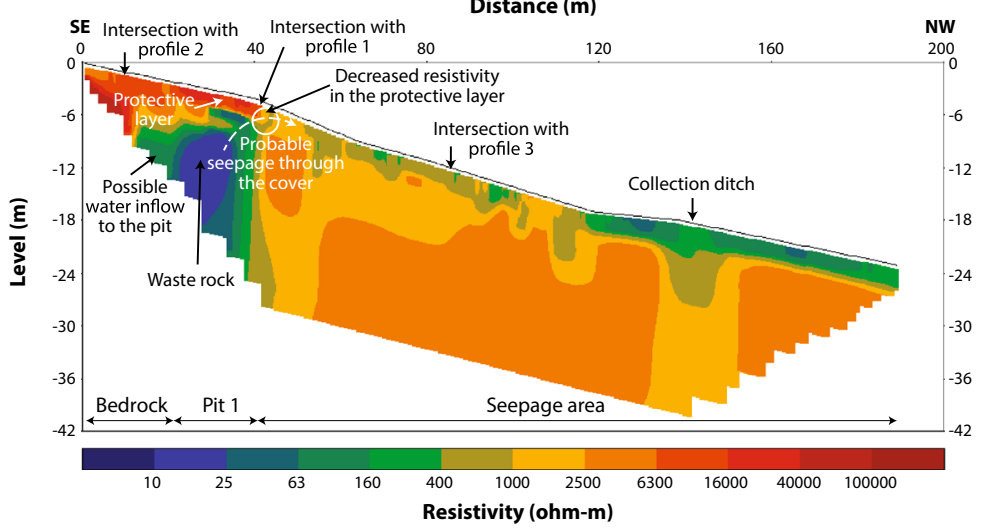


sulphide content of the rocks and because they are partially crushed to fines and damp. Recent drilling in the backfill indicated an average sulphur mass fraction of $2 \%$ for 20 waste rock samples, which is only relatively high for a mine waste deposit, but certainly higher than the average sulphidic content of the bedrock. The resistivity variations within the waste may be explained by the heterogeneity of the material. In addition to the petrological variability of the rocks, variations in particle size and moisture content may affect the electrical properties of the waste rock, as illustrated by Anterrieu et al. (2010). The production or storage of acidic drainage in the sulphide material may also alter the bulk resistivity by decreasing its values (Campbell and Fitterman 2000). Most of the studies of tailings ponds and waste rock piles using geoelectrical methods have observed heterogeneity in the resistivity of the waste and suggested similar interpretations for it (e.g. PlacienciaGómez et al. 2010; Martín-Crespo et al. 2010; Anterrieu et al. 2010; Grangeia et al. 2011). Another factor which probably accounts for resistivity variations in the backfilled material at Kimheden is that, along with waste rock, other types of materials such as contaminated soils and organic matter, have been dumped in the pits. This additional source of heterogeneity makes it difficult to associate lowresistivity areas in the backfilled waste with geochemical properties (sulphide content), geotechnical properties (particle size and pore water content) or processes (AMD generation).

\section{Fractures and groundwater flow paths}

Geotechnical drill core logging and archive documents about the site indicate that the rock substratum close to the pits is generally fractured but also contains individual larger-scale cracks that account for the major part of the water inflow to the pits. Evidence of fractured bedrock or single fractures was therefore a special focus of the geophysical investigations. The objectives were to identify potential zones of water and oxygen ingress into the backfilled material of open pit 1 which produces the greatest quantities of pollutants, and to determine the pathways of contaminated drainage from the pit. Reflections indicating fractures in the shallow bedrock and natural till cover close to the walls of the pit could be found on some of the GPR sections. However, more readily identifiable signatures of the fractured bedrock could be observed in the resistivity models and some results are described hereafter.

Profile 2 is located in the bedrock above backfilled open pit 1 (Fig. 2). The resistivity values in the rock substratum are high $(>16,000 \Omega \mathrm{m}$, Fig. $6 \mathrm{~b})$, whereas the natural till cover and the topsoil layer are less resistive $(<6,300 \Omega \mathrm{m})$. The noticeable superficial horizontal variations in the resistivity of the bedrock could be caused by petrological variations, but they may also indicate different degrees of alteration of the bedrock, with zones of weaker bedrock associated with lower resistivity values. Parasnis (1973) presented a geoelectrical survey performed in the context of prospecting campaigns at Kimheden, and he showed that weathering of the host rock had a major influence on the apparent resistivity, whereby highly weathered zones in the host rock had the potential to mask the conductive ore anomaly. In this sense, the large conductive anomaly at the bottom of the profile (resistivity values down to $1,000 \Omega \mathrm{m}$ ), could be the signature of a major water-filled fracture zone. However, the significant size and the shape of the anomaly strongly influence the consideration of side effects from the nearby pit instead, as discussed later in "Geoelectrical multiple-gradient array survey (backfilled open pit 1)".

Profile 4 crosses the pit and the bedrock below the pit (Fig. 2). The inverted section (Fig. 6d) shows that the limit at the higher edge of the pit between the low-resistivity zone consisting of the backfilled waste and the higher resistivity in the bedrock is not vertical, in contrast to the limit at the lower edge and contrary to topographical archive data. This suggests that the higher wall is a weaker barrier compared to the lower wall in this section of the pit. Fractures and possibly inflows of groundwater may be expected at this location.

Profile 3 is located in the bedrock below backfilled open pit 1 (Fig. 2). On the inverted resistivity section (Fig. 6c), the first half of the profile is characterised by reduced resistivity values on the surface, going down to $160 \Omega \mathrm{m}$ while the other half of the profile has resistivity values higher than $2,500 \Omega \mathrm{m}$ on the surface. Decreased resistivity values are also observed on the surface of profile 4 (Fig. 6d) below the intersection with the pit. Observations in the field show that in this area, situated downstream of open pit 1 , the bedrock is largely covered by peat and is constantly humid. It is known to be the seepage area from backfilled open pit 1 . Water on the surface is ion-rich, with electrical conductivities of $\sim 600 \mu \mathrm{S} \mathrm{cm}^{-1}$. The resistivity models allow to delimit this seepage area on the surveyed profiles, between 0 and $110 \mathrm{~m}$ on line 3 , and 40 to $200 \mathrm{~m}$ on line 4 . They also suggest, for the two profiles, that the major pathways of contaminated drainage occur on the surface and in the shallow subsurface. Resistivity variations in the deeper bedrock are not large enough for individual pathways of contaminated water to be identified, even though the material may be fractured. One single low-resistivity anomaly is observed in the deeper bedrock at the bottom right of profile 3 (Fig. 6c), but the presence of noise on the pseudo-section of apparent resistivity data suggests that this is likely to be an artefact. 
Profile 4 gives additional information about the pathways of mine drainage. The profile runs along the slope and intersects a ditch downstream of pit 1 (Figs. 2, 6d) that was designed to divert contaminated water to a treatment pond located at the bottom of the hill. Low-resistivity values of less than $160 \Omega \mathrm{m}$ are found on the surface of the profile below the intersection with the ditch (from $150 \mathrm{~m}$ to the end of the profile), indicating that contaminated surface water runs beyond the ditch. This observation implies that the ditch fails to retain all the drainage, which is in agreement with water flow data previously obtained in the stream (Villain et al. 2013).

\section{Implications for the evaluation of the reclamation}

\section{Dry cover}

The results obtained using geophysical methods at $\mathrm{Ki}$ mheden did not reveal any major fracture or vertical displacement in the sealing layer. However, two types of risk of deterioration of the sealing layer were recognised.

The variations in the thickness of the protective layer observed with the GPR and geoelectrical surveys could be the result of an attempt to level the irregular surface of the spoil during deposition of the dry cover. In the Kristineberg mining area where the Kimheden mine is located, the limit of frost penetration in the protective layers made of local till has been estimated to be less than $1.5 \mathrm{~m}$ deep (Höglund and Herbert 2004), which is why a thickness of $1.5 \mathrm{~m}$ was selected for the protective layer at the site. Protection of the sealing layer from frost action is essential, as freezing and thawing effects in clayey till layers may lead to increased hydraulic conductivity (Carlsson and Elander 2001). Results from the GPR survey indicated, however, regions of the pits where the protective layer is thinner than $1.5 \mathrm{~m}$, which could imply decreased performance of the cover over the long term through enhanced permeability in the sealing layer, resulting in increased oxygen diffusion. Experience with dry covers at other sites has shown that deterioration and increased permeability of sealing layers with time are not uncommon (Waygood and Ferreira 2009).

The geoelectrical results at backfilled open pit 1 indicated seepage of mine drainage through the dry cover (Fig. 6d), which is explained by the sloping topography of the terrain. In this area, patches of oxidation or actual seepage during periods of higher water flow can be observed on the surface of the cover. It is assumed that these oxidation patches are caused by precipitation of iron, which is dissolved in the drainage seeping through the cover, when it comes into contact with air and oxidises. Seepage through the dry cover generates a risk of erosion for the sealing layer. One option to reduce this risk would have been to include an oxygen-controlled drainage system underneath the sealing layer to allow the drainage from the mine waste to run out freely above the lower edge of the pit without letting the oxygen reach the waste.

Fractures and groundwater flow pathways

Data from a previous study (Rosén and Wilske 1994) and both the resistivity and GPR sections obtained in this study indicate that the upper rock substratum surrounding backfilled open pit 1 is fractured. Therefore, it is reasonable to think that the pit walls are pervious to oxygen and/or oxygen-containing water. A continuous flow of water and oxygen through the pits may therefore result in persistent oxidation of the sulphidic waste and washout of the oxidation products. Failure to keep the backfilled waste in oxygen-poor conditions inevitably compromises the performance of the backfilling and sealing work. That may explain the ongoing production of AMD from the waste rock 14 years after reclamation of the site (Villain et al. 2013). The problem with fractured bedrock surrounding the pits had already been raised by Rosén and Wilske (1994) before completion of the reclamation, as they suggested sealing of the fractures as a reclamation alternative to the application of a dry cover. They recognised that this option would result in a much more effective reduction of the water inflow into the pits compared to the dry cover, as most of the inflow occurs as groundwater. They considered, however, that restriction of the oxygen contact with the waste using a dry cover would work better in decreasing AMD generation than decreasing water inflow, as they assumed that groundwater does not usually contain a large amount of oxygen. However, as the fractures in the pit walls are relatively superficial, transport of air or oxygencontaining groundwater cannot be ruled out.

\section{Limitations of the study}

\section{GPR survey}

When evaluating the thickness of the protective layer and the integrity of the sealing layer using GPR, potential sources of error must be taken into account, arising mainly from uncertainties in the interpretation of the data and in the propagation velocity models. The two types of uncertainties are discussed separately.

Uncertainties in the interpretation of the data lie in the choice of the correct reflection for the sealing layer. Multiple superficial reflections were observed on most of the GPR profiles, which, according to the velocity model and the expected thickness of the protective layer $(1.5 \mathrm{~m})$, turned 
out to be too close to the surface to be interpreted as the sealing layer. These reflections should therefore belong to the protective layer, so a deeper reflection was selected for the sealing layer. Note that selecting the correct reflection in this way relies on an accurate propagation velocity model. The risk of choosing a wrong reflection was greater for backfilled open pit 1, where attenuation of the GPR signals at depth occurred more rapidly than for backfilled open pit 2 , and the reflection from the sealing layer was therefore much less distinct. Lower penetration depth of the GPR signals on backfilled open pit 1 could be explained by more humid conditions in the protective layer, resulting in higher conductivity of the till. To try to achieve some accuracy in the correct choice of reflection for the sealing layer, its depth at the reference point $(1.5 \mathrm{~m})$ and the velocity model were used; the reflection at every other profile was then determined stepwise (see "Analysis of GPR data"). The GPR data at backfilled open pit 2 were of higher quality and the sealing layer signature was more distinct (Fig. 5). The interpretation model for the sealing layer is therefore more reliable, even though superficial reflections were also encountered. The origin of these superficial reflections could be heterogeneities in the composition of the till protective layer, layering during deposition of the protective layer, local water tables from perched aquifers lying on the sealing layer, remains of frost etc.

Uncertainties in the propagation velocity models arise mostly from the assumption that the protective layer is vertically homogeneous, as they are supposed to represent the protective layer all the way down to the sealing layer, but are only based on the travel time of the direct (i.e. surface) waves. This was considered a good hypothesis for backfilled open pit 2 , which was characterised by fairly dry conditions (i.e. the probability of significant variations in the propagation velocity across the protective layer is low), but for the more humid backfilled open pit 1 (i.e. the probability of large variations in the propagation velocity across the protective layer is higher), the validity of the assumption is reduced. It should also be noted that the direct waves travelling close to the ground surface are always influenced by air, which could lead to some overestimation of the propagation velocity. However, relatively good agreement between the protective layer thickness model and the actual thickness at the four control sample pits of backfilled open pit 2 (see "Thickness of the protective layer"), shows that the propagation velocity model chosen for this pit was valid.

Geoelectrical multiple-gradient array survey (backfilled open pit 1)

The multiple-gradient array has the potential to generate good horizontal-vertical resolution resistivity images with acceptable signal-to-noise ratio (Dahlin and Zhou 2006). The mean residual obtained from the resistivity inversion at profile 1 ( $11.7 \%$, Fig. 6a), however, tends to indicate flaws in the data quality. Two likely reasons why the resistivity data obtained at line 1 have been more affected by noise contamination than the other profiles (having residuals lower than $3.6 \%$, Fig. 6b-d) are the current injection conditions in the field and the existence of side effects. Most of profile 1 has been surveyed in an environment with a resistive surface layer (protective cover of till) overlying a conductive medium (waste rock). Therefore, as mentioned in "Geoelectrical multiple-gradient arrays", contact between electrodes and the ground was poor and the injection of current was rendered difficult. The same difficulty was encountered in a geoelectrical survey on tailings covered by a resistive surface layer of dry sand reported by King (1994). In addition to these measurement obstacles experienced at line 1 , side effects may have contributed to reduce the data quality. Side effects are effects that can be encountered when surveying 2-D profiles in 3-D environments, as the injected current travels in three dimensions. At line 1, where the surveying line runs close along the edges of the narrow pit (Fig. 2), these effects were probably inevitable. They can be easily identified in the 20 to $70 \mathrm{~m}$ section of the profile (Fig. 6a), where resistivity values decrease with depth due to the very close distance to the backfilled conductive waste. In the 115 to $150 \mathrm{~m}$ section, the large resistive shape at depth might also be explained by side effects, whereby proximity to the bedrock may have artificially increased the apparent resistivity values. Multiple side effects at line 1 have probably contributed to the introduction of noise in the geoelectrical data. Another possible case of side effect is the large low-resistive anomaly found at the bottom of profile 2 (Fig. 6b). Influence of low resistivities in the nearby pit may have caused this pattern, as the current travels longer distances at depths and gets more influenced by the side resistivities. Nevertheless, the interpretation of a large water-filled fracture as suggested instead in "Fractures and groundwater flow paths" is still possible. The recognition of side effects is important in order to avoid misleading interpretations of resistivity variations. An alternative to avoid these effects would have been to use 3-D geoelectrical surveying but, at the present time, costs of 3-D surveying remain prohibiting (Loke 2014). In the present study, crossing of the profiles has, to some extent, benefited to the recognition of side effects and interpretation of the geoelectrical data.

The image of the groundwater table in backfilled open pit 1 shown on Fig. 6a is an approximation based on the groundwater levels measured in the two wells placed in the backfill, but the groundwater table could not be resolved by the geoelectrical data. In an attempt to evaluate why the 
geoelectrical data could not identify the position of the water in the backfilled open pit, a 2-D conceptual model of the true resistivity distribution in and around the pit was created. The model included the resistivity of the watersaturated waste rock deduced from electrical conductivity measurements of the groundwater in the backfill and expected porosity and cementation grade of the waste rock. The apparent resistivity values from this distribution were then calculated with the forward modelling software RES2DMOD for the multiple-gradient array and later inverted in RES2DINV. The modelling results indicate that the groundwater table cannot be resolved, since the intermediate resistivity values of the water-saturated and unsaturated waste rock are suppressed between the low and high-resistivity bodies observed in the pit. PlacienciaGómez et al. (2010) observed that low resistivity in mine waste is more likely to be related to high ion concentrations in the pore water rather than to moisture of the waste. It is, therefore, reasonable to assume that regions of active sulphide oxidation and generation of ion-rich pore water in the backfilled waste are better mapped by the geoelectrical data than the presence of groundwater.

According to aerial mapping over the mine before completion of the reclamation, the floor of the pit should be found at a depth of 10 to $20 \mathrm{~m}$ below the current surface of the dry cover. However, it was not imaged by the geoelectrical data, suggesting that the actual penetration depth of the signals has to be lower than indicated on the inverted sections. Other geoelectrical studies of mine tailings and waste rock deposits have succeeded in imaging the floor of the tailings impoundments or the underlying bedrock (Placiencia-Gómez et al. 2010; Martín-Crespo et al. 2010; Gómez-Ortiz et al. 2010; Martínez-Pagán et al. 2011; Mele et al. 2013). Forward modelling of the resistivities in the pit under perfect measuring conditions (no noise) allowed detection of the underlying bedrock, which shows that this is probably a practical issue in this study. The most reasonable explanation is that, due to high resistivity in the upper till layer, the contact resistance between the electrodes and the ground was very high (see "Geoelectrical multiple-gradient arrays" and earlier in this section), making it impossible to inject the necessary current in order to penetrate beneath the conductive zone of the pit.

\section{Conclusions}

This study illustrated how GPR and geoelectrical multiplegradient array surveying can be used to provide beneficial information about the effectiveness of reclamation of an open pit. The survey carried out at the Kimheden mine site identified weaknesses in the reclamation measures 14 years after their application.
1. Risks of damage to the sealing layer in the dry cover over the long term were recognised with both methods. Models constructed with GPR data showed variations of up to $1 \mathrm{~m}$ in the thickness of the protective layer on backfilled open pits, which could also be observed in the resistivity models. In some areas of the pits, the thickness was lower than $1.5 \mathrm{~m}$, which implies a risk of deterioration of the underlying sealing layer by frost action. Seepage from the backfilled waste through the cover was identified with the geoelectrical survey, which may be a source of erosion of the sealing layer. Some portions of the cover may therefore already now, or in the future, allow an increased diffusion of oxygen to the backfilled waste.

2. Resistivity models at backfilled open pit 1 showed a possible inflow of shallow groundwater through the pit wall. Outflow of contaminated water from the pit was observed in the upper bedrock and on the ground surface. Extension of the contaminated seepage area beyond the collection ditch demonstrated its inefficacy in retaining the drainage. Shallow fractures in the pit walls are suggested to be possible pathways for oxygen into the backfilled mine waste.

Although geophysical data on their own cannot be expected to provide a complete picture of the effects of a reclamation approach, their integration with reference data allowed identification of deficiencies that compromised the performance of the reclamation at the Kimheden open-pit site, which may therefore provide insights for further improvement of mitigation practices.

Acknowledgments This study was financed by the European Union's Structural Funds through the non-profit organisation Georange in Sweden. The authors also would like to thank Bert-Sive Lindmark at Bergteamet for his help in the field, Carl-Axel Triumf, formerly at GeoVista, for valuable advice on the design of the survey and in the interpretation of the data, Peter Liikamaa at MRM for realising the geotechnical control of the cover, Prof. Thorkild Maack Rasmussen at Luleå University of Technology (LTU) for kindly offering to review the manuscript, an anonymous reviewer for his beneficial comments and Milan Vnuk at LTU for helping with the figures.

Open Access This article is distributed under the terms of the Creative Commons Attribution License which permits any use, distribution, and reproduction in any medium, provided the original author(s) and the source are credited.

\section{References}

Abu-Zeid N, Bianchini G, Santarato G, Vaccaro C (2004) Geochemical characterisation and geophysical mapping of Landfill leachates: the Marozzo canal case study (NE Italy). Environ Geol 45:439-447

Allen RL, Weihed P, The Global VHMS Research Project Team (2002) Global comparison of volcanic-associated massive sulphide districts. J Geol Soc Lond Spec Publ 204:13-37 
Anterrieu O, Chouteau M, Aubertin M (2010) Geophysical characterization of the large-scale internal structure of a waste rock pile from a hard rock mine. Bull Eng Geol Environ 69:533-548

Årebäck H, Barrett TJ, Abrahamsson S, Fagerström P (2005) The Palaeoproterozoic Kristineberg VMS deposit, Skellefte district, northern Sweden, part I: geology. Miner Deposita 40:351-367

Axelsson C-L, Ekstav A, Holmén J, Jansson T (1991) Efterbehandling av sandmagasin i Kristineberg, Hydrogeologiska förutsättningar för åtgärdsplan. Lakvattenbalanser och vittringsbegränsande åtgärder. Golder Geosystem AB, Uppsala, Sweden. Internal report (in Swedish)

Bambic DG, Alpers CN, Green PG, Fanelli E, Silk WK (2006) Seasonal and spatial patterns of metals at a restored copper mine site. I. Stream copper and zinc. Environ Pollut 144:774-782

Bergström J (1997) Development of a geophysical method for investigating and monitoring the integrity of sealing layers on mining waste deposits. Final report. AFR-report 164, SEPA, Stockholm, Sweden

Brake SS, Connors KA, Romberger SB (2001) A river runs through it: impact of acid mine drainage on the geochemistry of West Little Sugar Creek pre- and post-reclamation at the Green Valley coal mine, Indiana, USA. Environ Geol 40:1471-1481

Buselli G, Lu KL (2001) Groundwater contamination monitoring with multichannel electrical and electromagnetic methods. J Appl Geophys 48:11-23

Campbell DL, Fitterman DV (2000) Geoelectrical methods for investigating mine dumps. In: ICARD 2000-proceedings from the fifth international conference on acid rock drainage, Denver, USA, pp 1513-1523

Carlsson E, Elander P (2001) Investigation of repeated cycles of freezing and thawing effects on a clayey till used as sealing layer over sulphide-rich tailings at the Kristineberg mine, northern Sweden. In: Proceedings of securing the future. International conference on mining and the environment, Skellefteå, 25 June1 July, vol 1, pp 58-71

Dahlin T, Zhou B (2006) Multiple-gradient array measurements for multichannel 2D resistivity imaging. Near Surf Geophys 4:113-123

Dahlin T, Rosqvist H, Leroux V (2010) Resistivity-IP mapping for landfill applications. Near Surf Geosci 28:101-105

Edström and Schönfeldt AB (1996) Kristinebergsgruvan, Efterbehandlingsarbeten. Edström \& Schönfeldt $\mathrm{AB}$ and Boliden $\mathrm{AB}$, Sweden. Internal report (in Swedish)

Gómez-Ortiz D, Martín-Crespo T, Esbrí JM (2010) Geoenvironmental characterization of the San Quintín mine tailings, Ciudad Real (Spain). Dyna 161:131-140

Grangeia C, Ávila P, Matias M, da Silva EF (2011) Mine tailings integrated investigations: the case of Rio tailings (Panasqueira Mine, Central Portugal). Eng Geol 123:359-372

Hannington MD, Kjarsgaard IM, Galley AG, Taylor B (2003) Mineral-chemical studies of metamorphosed hydrothermal alteration in the Kristineberg volcanogenic massive sulfide district, Sweden. Miner Deposita 38:423-442

Hellman H, Lokrantz H (2008) Kimhedengruvan, Installation av grundvattenrör vid nedlagt och igenfyllt dagbrott vid Kimheden. Berggeologiska Undersökningar AB, Sweden. Internal report (in Swedish)

Höglund LO, Herbert R (Eds), Lövgren L, Öhlander B, Neretnieks I, Moreno L, Malmström M, Elander P, Lindvall M, Lindström B (2004) MiMi-performance assessment: main report. MiMi report 2003:3, Mitigation of the environmental impact from mining waste programme (MiMi). MiMi Print, Luleå, Sweden

Holmström H, Salmon UJ, Carlsson E, Petrov P, Öhlander B (2001) Geochemical investigations of sulfide-bearing tailings at Kristineberg, northern Sweden, a few years after remediation. Sci Total Environ 273:111-133
INAP (The International Network for Acid Prevention) (2009) Global Acid Rock Drainage Guide (GARD Guide). Chapter 6. http:// www.gardguide.com/. Last Accessed 11th July 2014

King A (1994) Application of geophysical methods for monitoring acid mine drainage. MEND Project 4.6.1. CANMET, Ottawa, Ontario, Canada

Loke MH (2014) Tutorial: 2-D and 3-D electrical imaging surveys. Geotomo Software, Malaysia

Loke MH, Acworth I, Dahlin T (2003) A comparison of smooth and blocky inversion methods in 2D electrical imaging surveys. Explor Geophys 34:182-187

Malmström M, Werner K, Salmon U, Berglund S (2001) Hydrogeology and geochemistry of mill tailings impoundment 1 , Kristineberg, Sweden: Compilation and interpretation of preremediation data. MiMi report 2001:4, Mitigation of the environmental impact from mining waste programme (MiMi). MiMi Print, Luleå, Sweden

Martín-Crespo T, De Ignacio-San José C, Gómez-Ortiz D, MartínVelázquez S, Lillo-Ramos J (2010) Monitoring study of the mine pond reclamation of Mina Concepcion, Iberian Pyrite Belt (Spain). Environ Earth Sci 59:1275-1284

Martínez-Pagán P, Faz A, Acosta JA, Carmona DM, MartínezMartínez S (2011) A multidisciplinary study for mining landscape reclamation: a study case on two tailing ponds in the Region of Murcia (SE Spain). Phys Chem Earth Parts A/B/C 36:1331-1344

Mele M, Servida D, Lupis D (2013) Characterisation of sulphidebearing waste-rock dumps using electrical resistivity imaging: the case study of the Rio Marina mining district (Elba Island, Italy). Environ Monit Assess 185:5891-5907

Nobes DC, Armstrong MJ, Close ME (2000) Delineation of a landfill leachate plume and flow channels in coastal sands near Christchurch, New Zealand, using a shallow electromagnetic survey method. Hydrogeol J 8:328-336

Parasnis DS (1973) Mining geophysics: methods in geochemistry and geophysics series (3), 2nd edn. Elsevier, Amsterdam

Placiencia-Gómez E, Parviainen A, Hokkanen T, Loukola-Ruskeeniemi K (2010) Integrated geophysical and geochemical study on AMD generation at the Haveri $\mathrm{Au}-\mathrm{Cu}$ mine tailings, SW Finland. Environ Earth Sci 61:1435-1447

Poisson J, Chouteau M, Aubertin M, Campos D (2009) Geophysical experiments to image the shallow internal structure and the moisture distribution of a mine waste rock pile. J Appl Geophys 67:179-192

Porsani JL, Filho WM, Elis VR, Shimeles F, Dourado JC, Moura HP (2004) The use of GPR and VES in delineating a contamination plume in a landfill site: a case study in SE Brazil. J Appl Geophys 55:199-209

Rosén L, Wilske Å (1994) Beräkningar av metallflöden och förslag till åtgärder vid Kimhedengruvan, Kristineberg. Scandiaconsult Väst AB, Sweden. Internal report (in Swedish)

Rubin Y, Hubbard SS (2005) Introduction to hydrogeophysics. In: Rubin Y, Hubbard SS (eds) Hydrogeophysics. Springer, Dordrecht, pp 3-21

Rucker DF, Glaser DR, Osborne T, Maehl WC (2009) Electrical resistivity characterization of a reclaimed gold mine to delineate acid rock drainage pathways. Mine Water Environ 28:146-157

Runkel RL, Bencala KE, Kimball BA, Walton-Day K, Verplanck PL (2009) A comparison of pre- and post-remediation water quality, Mineral Creek, Colorado. Hydrol Process 23:3319-3333

Tavakoli S, Elming S-Å, Thunehed H (2012) Geophysical modelling of the central Skellefte district, Northern Sweden; an integrated model based on the electrical, potential field and petrophysical data. J Appl Geophys 82:84-100

Van Dam R, Gutierrez L, McLemore V, Wilson GW, Hendrickx J, Walker B (2005) Near surface geophysics for the structural 
analysis of a mine rock pile, northern New Mexico. In: The 2005 National Meeting of the American Society of Mining and Reclamation, ASMR Lexington, USA, pp 1178-1201

Villain L, Alakangas L, Öhlander B (2013) The effects of backfilling and sealing the waste rock on water quality at the Kimheden open-pit mine, northern Sweden. J Geochem Explor 134:99-110
Waygood CG, Ferreira S (2009) A review of the current strategy for capping mining spoils. In: Proceedings of the International Mine Water Conference. Water Institute of Southern Africa and International Mine Water Association (IMWA), Pretoria, South Africa, pp 738-745 